Original Research

\title{
Femoral acetabular impingement labral pathology on MRI is correlated with greater hip flexion and decreased abduction in collegiate water polo players: A pilot study
}

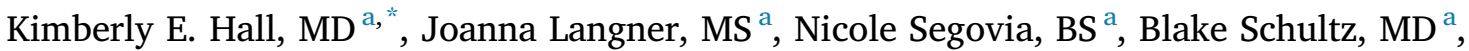 \\ Thomas Andriacchi, $\mathrm{PhD}^{\mathrm{c}}$, Garry Gold, $\mathrm{MD}^{\mathrm{a}, \mathrm{b}, \mathrm{c}}$, Marc R. Safran, $\mathrm{MD}^{\mathrm{a}}$ \\ ${ }^{a}$ Orthopedic Surgery Department, Stanford Hospital and Clinics, 450 Broadway St, Pavilion A, Redwood City, CA, 94063, USA \\ ${ }^{\mathrm{b}}$ Radiology Department, Stanford Hospital and Clinics, 300 Pasteur Dr., Stanford, CA, 94305, USA \\ c Mechanical Engineering Department, Stanford University, Building 530, 440 Escondido Mall, Stanford, CA, 94305, USA
}

\section{A R T I C L E I N F O}

\section{Keywords:}

Water polo

Athletes

Biomechanics

Hip

Motion analysis

Femoroacetabular impingement

Magnetic resonance imaging

\begin{abstract}
A B S T R A C T
Objectives: Femoroacetabular impingement (FAI) morphology is associated with hip pain and disability. Water polo players utilise the egg beater motion (method of treading water with legs rotating like an "egg beater"), and it is currently unclear what the relationship is between an egg beater and FAI morphology. Our objective was to associate hip range of motion during egg beater motion to MRI findings.

Methods: Eight National Collegiate Athletic Association (NCAA) Division 1 varsity water polo athletes (5 females and 3 males) were filmed at orthogonal views performing the egg beater motion using two waterproof cameras in synchrony. A model-based image-matching technique was used to determine hip joint angles which were recorded from the software. These athletes also underwent noncontrast MRI scans of both hips using a 3T MRI scanner and completed an 33-item International Hip Outcome Tool (iHOT-33) hip pain outcomes questionnaire. Descriptive statistics are reported as counts and percentages for categorical variables and as means, standard deviations, and a five-number summary for continuous variables. Relationships between the range of motion measures with MRI measures and with iHOT33 scores were analysed using linear regression models. All statistical analyses were completes using a two-sided level of significance of 0.05 .

Results: The average alpha angles for the right and left hips were $71.8^{0} \pm 7.5^{0}$ and $74.1^{0} \pm 8.4^{0}$, respectively. There was no statistically significant correlation between hip range of motion in any plane and alpha angle or lateral centre edge angle (CEA) on MRI. The average iHOT33 was $85.9 \pm 18.9$. Participants who had a labral tear had significantly smaller hip abduction ranges than participants who did not have a labral tear $\left(29^{\circ} \pm 4.1\right.$ vs. $35.3^{\circ} \pm$ $0.6, \mathrm{p}=0.02$ ), and those who had a labral tear had significantly increased hip flexion during egg beater kicking as compared with participants who did not have a labral tear $\left(28.2^{\circ} \pm 6.1\right.$ vs. $\left.16.3^{\circ} \pm 4, \mathrm{p}=0.02\right)$. There were no differences between right and left alpha angles or between right and left CEA.

Conclusion: There were no significant correlations between hip range of motion and alpha angle or CEA, but hips with labral pathology had greater hip flexion and more limited hip abduction ranges.
\end{abstract}

\footnotetext{
* Corresponding author. Tel.: +(650) 4979586.

E-mail address: kehall19@gmail.com (K.E. Hall).
} 


\section{What are the new findings?}

- This study shows that there is no significant correlation between hip range of motion and femoroacetabular impingement (FAI)related radiographic measurements.

- New findings show that labral pathology in the hips of water polo athletes are associated with greater hip flexion and more limited hip abduction ranges.

- This study sheds more light on the possible biomechanical basis of FAI in egg beater kicking, which contributes to our understanding of the development of FAI.

\section{Introduction}

The egg beater motion (rotating ones legs like "an egg beater") is a method of treading water that optimises energy expenditure and stability. Athletes in the sport of water polo utilise the egg beater motion throughout activity. In water polo, this motion is responsible for keeping the athletes above water so that they can use their arms to hold the ball, pass, shoot and defend.

Femoroacetabular impingement (FAI) is a disorder that causes hip pain and disability [1]. Anatomical variations of the acetabulum and/or femoral neck have been shown to contribute to FAI, labral tears, and possibly osteoarthritis [2,3]. Unfortunately, factors that contribute to these morphological changes are still unknown [4]. Athletes participating in sports involving forceful rotation and deep hip flexion are more prone to developing symptoms of FAI [5]. Sports commonly associated with FAI are soccer, ice hockey, basketball, tennis, golf, and dance [6,7]. There is limited research on the sport of water polo and even less on its association with FAI. An analysis of water polo injuries at the Fédération Internationale de Natation (FINA) World Championship and Olympic games found that $4.6 \%$ of injuries were related to the hip and groin; however, no specific mention on FAI is made [8]. This is also likely an underestimate of injuries given that this population of athletes would likely under-report injuries at this level until they were severe or significantly affecting performance. A recent study of water polo and synchronised swimming athletes also found that these aquatic athletes had a higher prevalence of FAI characteristics on MRI than the general population and a similar prevalence compared with athletes in other sports [9]. The cam lesion, typified by the loss of offset of the femoral head-neck junction, occurs at the proximal femoral growth plate during adolescence, from ages 9 to 17 years [10-12]. This deformity has been shown to be gradually acquired during skeletal maturation [13]. It is possible that the repetitive nature of the egg beater motion increases stress on the proximal femur owing to continued rotational motion with potential conflict between the femur and the acetabulum potentially putting an individual at risk of developing FAI anatomy and associated hip pain and labral pathology.

Understanding the biomechanics of (a) the egg beater motion at the hip joint and (b) how it correlates to MRI findings and FAI characteristics are important to understand possible injury patterns related to the hip in water polo. Our goal was to associate hip range of motion (ROM) during the egg beater motion to MRI findings. This may help to elucidate any relationship between rotational motion in the pool and FAI hip morphology.

\section{Methods}

This study was approved by the university institutional review board. Water polo players (men and women) from National Collegiate Athletic Association (NCAA) Division 1 university teams (about 40 in total) were contacted and invited to participate and signed the informed consent form. Athletes participated in two different activities, the first of which was performing the egg beater movement and being videotaped while in the water (between February 2018 and March 2018), while the second part included undergoing bilateral hip MRIs (between January 2019 and March 2019). Any players who were unable to complete both activities were excluded. All subjects filled out a questionnaire detailing how many average hours per week they tread water, how many years they have been in a sport that requires them to tread water, whether they have been diagnosed or treated for a hip injury, whether they have had surgery on either hip, and whether they have experienced hip pain at any point in their life. Lastly, participants completed the 33-item International Hip Outcome Tool (iHOT-33) which is a patient-reported measure designed to evaluate hip-related quality of life for nonarthritic hips [14].

\section{Part 1: egg beater ROM video capture}

The athletes were asked to perform the egg beater motion in the water while videotaped using two underwater GoPro Hero 2 cameras (720p, 60 fps, GoPro Inc., San Mateo, CA, USA). Each camera was $1.25 \mathrm{~m}$ away from the athlete in orthogonal positions, obtaining an anteroposterior (AP) and a profile (P) view of the player, and $0.45 \mathrm{~m}$ below the water surface. Each athlete was filmed for $1 \mathrm{~min}$, with both cameras filming simultaneously.

A model-based image-matching technique for uncalibrated videos was used as previously described [15]. The films were imported to the iMovie software (Apple, Cupertino, CA, USA). A synchronised movie where the AP (frontal) and P (lateral) view appeared in two windows side by side was created for each athlete. These movies were exported to the Poser software (Curious Labs Inc., Santa Cruz, CA). The software includes prebuilt humanoid models, and it is possible to move each joint of the model individually. Each athlete was analysed separately for the AP and the P view (Fig. 1). First, the model was matched to the athlete's body dimensions, starting with the pelvic segment and progressing distally (Fig. 1). For the hip, three degrees of motion were allowed (flexion-extension, abduction-adduction, and internal-external rotation). One hundred frames of each athlete were analysed in each view. Using the Poser software, the athletes were matched every 5 frames, resulting in 20 key frames for each athlete in each view. The software's interpolation feature calculated the intermediate frames. After all key images in a sequence were matched, a short film was obtained and checked for any errors. If any mismatch was detected, the key frames were rematched until a final adequate movie was achieved. This methodology was performed in accordance with Krosshaug et al. [15].

Hip joint angles were then recorded in a spreadsheet for each key frame. Abduction-adduction and internal-external rotation were recorded from the AP view, and flexion-extension of the hip was recorded from the $\mathrm{P}$ view. Data are presented as maximum angle in each movement direction, as well as the total arc.

\section{Part 2: MRI}

Each participant underwent a noncontrast unilateral hip MRI scan on each of their two hips (2 scans total) using a whole-body 3T MRI scanner (GE Healthcare, Waukesha, WI) with a 16-channel flexible phased-array receive-only coil (NeoCoil, Pewaukee, WI). The scanning protocol consisted of 5 MRI sequences (refer to supplemental information). To allow for consistency and to include the proximal femur in the image, the greater trochanter was palpated as a landmark and the coil was placed two inches below the iliac crest.

The RadiAnt DICOM viewer (Medixant, Inc) was used to analyse the images for each participant. Cam morphology was identified using the alpha angle measurement as described by Nötzli et al. (Fig. 2A) [3,16]. An alpha angle above $55^{\circ}$ was considered abnormal. Pincer morphology was identified using the measurement of the lateral centre edge angle (CEA) (Fig. 2B). Abnormal CEAs for acetabular dysplasia, representing instability in the hip, are those $<25^{\circ}$. Abnormal CEA for acetabular over coverage seen in pincer morphology is $>39^{\circ}$. The 


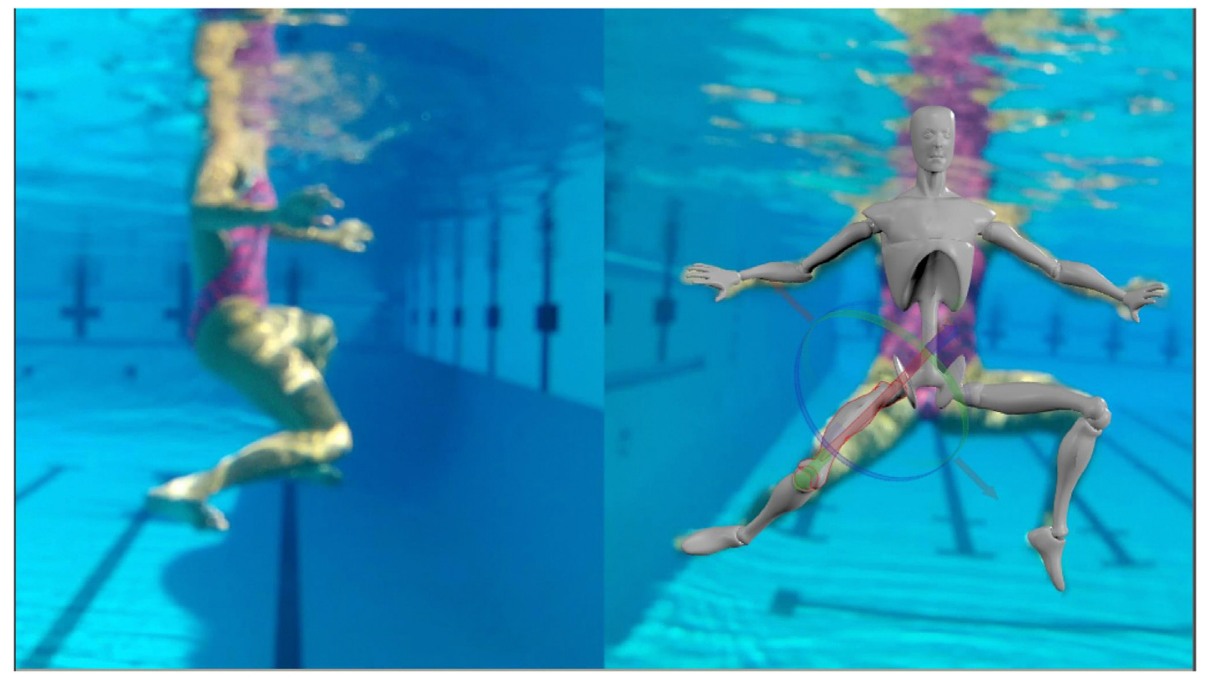

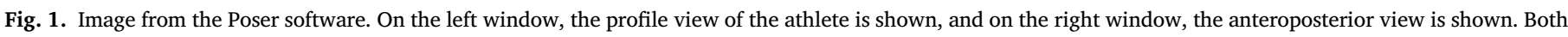

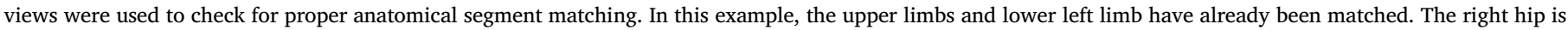
selected, and the "direct manipulation" tool will be used to match the right lower limb.

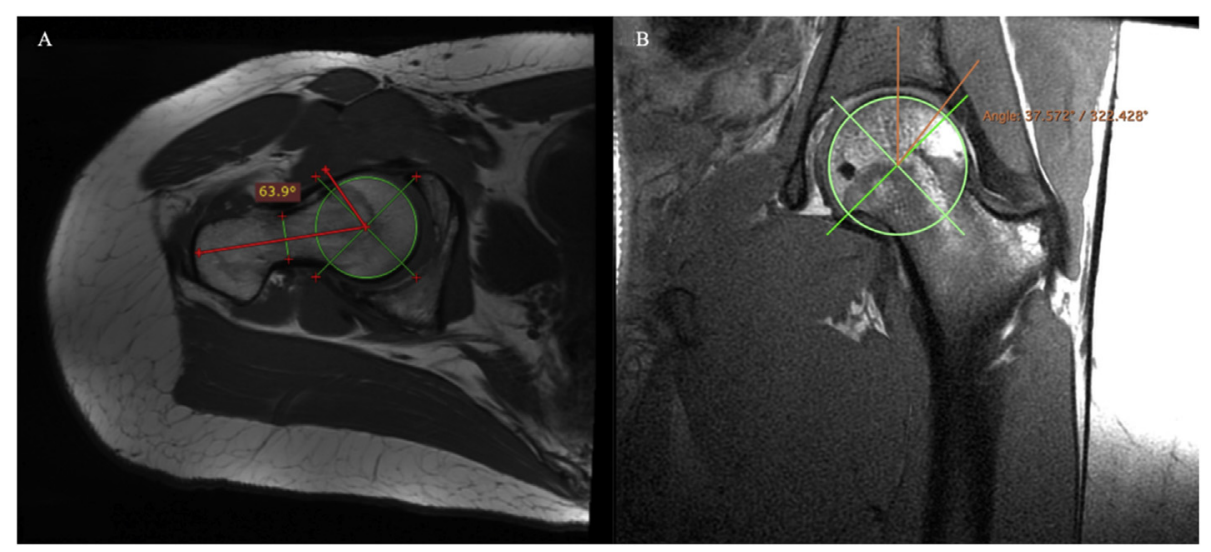

Fig. 2. A. Axial oblique T1-weighted image of the central slice from the right hip used to determine the alpha angle. B. Coronal image of a fusion of fat and water-only IDEAL-FSE scans from the left hip used to determine the CEA. IDEAL-FSE: Iterative decomposition of water and fat with echo asymmetry and least-squares estimation (IDEAL), fast spin echo (FSE); CEA: center edge angle.

presence of labral tears and cartilage damage was also identified by a board-certified musculoskeletal radiologist. Pincer morphology is usually measured using plain radiographs, and signs such as cranial retroversion, or crossover sign, were not assessed with this MRI methodology. However, to avoid unnecessary radiation risk to these young volunteers, MRI was selected as the modality for assessment of FAI anatomy, despite its limitations for measurement of lateral CEA. Angles were measured by two board-certified musculoskeletal radiologists and a student trained by those radiologists. For further details regarding the MRI methodology, please refer to the study by Langner et al. [9].

\section{Statistical analysis}

Descriptive statistics are reported as counts and percentages for categorical variables and as means and standard deviations. The relationships between ROM measures with MRI measures and with iHOT33 scores were analysed using linear regression models. Differences between right and left CEA and alpha angles were analysed using paired t-tests. ROM measures were also compared with patient history of labral tears and cartilage damage using two-sample t-tests. Effect sizes (Cohen's d) for each of these comparisons were added. All assumptions were tested,
Table 1

Demographic information.

\begin{tabular}{llll}
\hline Demographics & Frequency & & Percent \\
\hline Female & $5 / 8$ & & $62.5 \%$ \\
Previous hip surgery & $0 / 8$ & & $0 \%$ \\
Hip pain/injury & $1 / 8$ & & $12 \%$ \\
Right-handed & $6 / 8$ & & $75 \%$ \\
\hline & Average \pm SD & Min & Max \\
\hline Age (yrs) & $21.8 \pm 0.7$ & 21 & 23 \\
iHOT-33 & $85.9 \pm 18.9$ & 46.7 & 99.7 \\
Treading life hours (hours) & $9178 \pm 3300.8$ & 6240 & 16,640 \\
\hline
\end{tabular}

iHOT-33, 33-item International Hip Outcome Tool.

and statistical analyses were performed using RStudio, version 1.1.456 (Boston, MA, USA) using a two-sided level of significance of 0.05 .

Patient and public involvement

Patients or the public were not involved in the design, conduct, reporting, or dissemination plans of our research. 
Table 2

Hip joint angles during egg beater motion.

\begin{tabular}{|c|c|c|c|c|c|c|}
\hline & \multicolumn{2}{|l|}{ Male } & \multicolumn{2}{|l|}{ Female } & \multicolumn{2}{|l|}{ Both } \\
\hline & Mean $\left(^{\circ}\right)$ & SD & Mean $\left({ }^{\circ}\right)$ & SD & Mean $\left(^{\circ}\right)$ & SD \\
\hline External rotation & 37.3 & 2.0 & 53.0 & 11.0 & 26.6 & 23.6 \\
\hline Internal rotation & 32.3 & 31.4 & 21.2 & 18.9 & 47.1 & 12.9 \\
\hline Arc of rotation & 69.7 & 26.9 & 76.1 & 15.9 & 73.1 & 20.1 \\
\hline Abduction & 62.2 & 4.1 & 53.9 & 12.5 & 57 & 10.8 \\
\hline Adduction & $\mathrm{n} / \mathrm{a}$ & & $\mathrm{n} / \mathrm{a}$ & & $\mathrm{n} / \mathrm{a}$ & \\
\hline Arc of abd/add & 26.7 & 4.7 & 30.7 & 3.2 & 27.5 & 8.1 \\
\hline Flexion & 84.8 & 16.8 & 83.3 & 15.3 & 83.9 & 15.3 \\
\hline Extension & $\mathrm{n} / \mathrm{a}$ & & $\mathrm{n} / \mathrm{a}$ & & $\mathrm{n} / \mathrm{a}$ & \\
\hline Arc of flex/ext & 52.2 & 11.8 & 53.7 & 12.3 & 53.1 & 11.7 \\
\hline
\end{tabular}

Values represent the average and standard deviations of the maximum value observed for each athlete.

Table 3

MRI findings.

\begin{tabular}{lll}
\hline & Mean & SD \\
\hline Alpha angle (R) & 71.8 & 7.5 \\
Alpha angle (L) & 74.1 & 8.4 \\
Alpha angle (Max) & 77.0 & 6.7 \\
CEA (R) & 35.9 & 5.0 \\
CEA (L) & 38.0 & 7.4 \\
CEA (max) & 40.3 & 3.6 \\
\hline & Yes (\%) & No (\%) \\
\hline Cartilage damage (R) & $2(25 \%)$ & $6(75 \%)$ \\
Cartilage damage (L) & $2(25 \%)$ & $6(75 \%)$ \\
Cartilage damage (any) & $2(25 \%)$ & $6(75 \%)$ \\
Labral tear (R) & $5(62.5 \%)$ & $3(37.5 \%)$ \\
Labral tear (L) & $4(50 \%)$ & $4(50 \%)$ \\
Labral tear (Any) & $3(37.5 \%)$ & $5(62.5 \%)$ \\
\hline
\end{tabular}

CEA, central edge angle.

\section{Results}

Eight athletes participated in the study, for a total of 16 hips assessed. Five participants were women and three were men, with an average age of 21.8 years at the time of MRI. Seventy-five percent were right-handed. None underwent previous hip surgery, although one of eight subjects did have previous hip pain/injury (Table 1). Average external rotation on egg beater measurements of all participants was $26.6^{0} \pm 23.6^{0}$, while average internal rotation was $47.1^{0} \pm 12.9^{0}$ (Table 2).

The average alpha angles for the right and left hips were $71.8^{0} \pm 7.5^{0}$ and $74.1^{0} \pm 8.4^{\circ}$, respectively. The average CEAs for the right and left hips were $35.9^{0} \pm 5.0^{0}$ and $38.0^{0} \pm 7.4^{0}$, respectively (Table 3). A quarter of right hips and a quarter of left hips had evidence of articular cartilage damage, while more than half of right hips had evidence of a labral tear and half of left hips had a labral tear. There was no statistically significant correlation between hip ROM in any plane (abduction/ adduction, flexion/extension, or rotation) and alpha angle or CEA on MRI.

Participants who had articular cartilage damage noted on MRI had significantly higher minimum abduction (side-to-side) measurements than participants who did not have cartilage damage $\left(40^{0} \pm 1.4^{0}\right.$ vs. $27.2^{0}$ $\pm 10.3^{0}, \mathrm{p}=0.03$ ), specifically when assessing the right hip. Participants who had a labral tear on MRI had significantly smaller abduction (sideto-side) ranges than participants who did not have a labral tear $\left(26^{0} \pm 2.6^{0}\right.$ vs. $\left.32^{0} \pm 3.5^{0}, p=0.04\right)$, specifically when assessing the left hip.

Participants who had a labral tear had significantly smaller hip abduction (side-to-side) ranges than participants who did not have a labral tear $\left(29^{0} \pm 4.1^{0}\right.$ vs. $\left.35.3^{0} \pm 0.6^{0}, \mathrm{p}=0.02\right)$. Participants who had a labral tear had significantly higher hip flexion (bend) measures than participants who did not have a labral tear $\left(28.2^{0} \pm 6.1^{0}\right.$ vs. $16.3^{0} \pm 4^{0}$ degrees, $\mathrm{p}=0.02$ ) (Figs. $3 \mathrm{~A}$ and $\mathrm{B}$ ).

As for the leg dominance, there were no significant differences between right and left alpha angles $(\mathrm{p}=0.56)$ and no differences between right and left CEA $(\mathrm{p}=0.48)$ when using paired t-tests. There was also no significant correlation between hip ROM and iHOT-33 scores as well as between hip ROM and lifetime treading water hours.

\section{Discussion}

The purpose of this pilot study was to investigate associations between hip ROM during the egg beater motion used in water polo and hip MRI findings. The goal was to help elucidate possible risk factors of the egg beater motion in water polo players with special attention to the hip joint. Understanding how joint kinematics may relate to MRI findings can be helpful in the evaluation of injury patterns and patients at risk.

FAI morphology is common in asymptomatic athletic populations, with a prevalence of $54.8 \%$ [17]. Even in asymptomatic individuals, FAI morphology may alter biomechanics in certain activities [6]. Sports such

\section{A. Delta Side (Max) vs. Labral Tear (Any)}

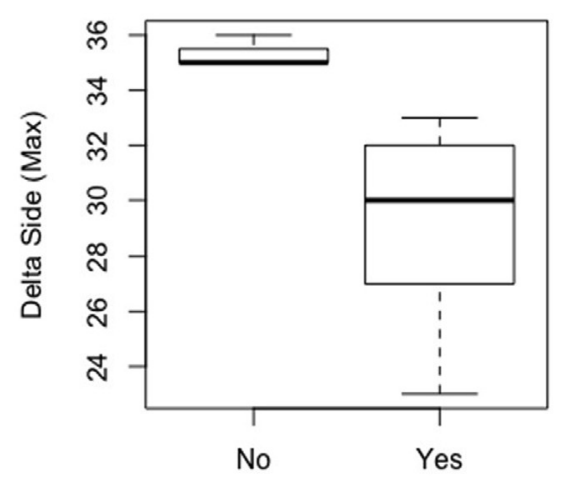

Labral Tear (Any)

\section{B. Min Bend (Min) vs. Labral Tear (Any)}

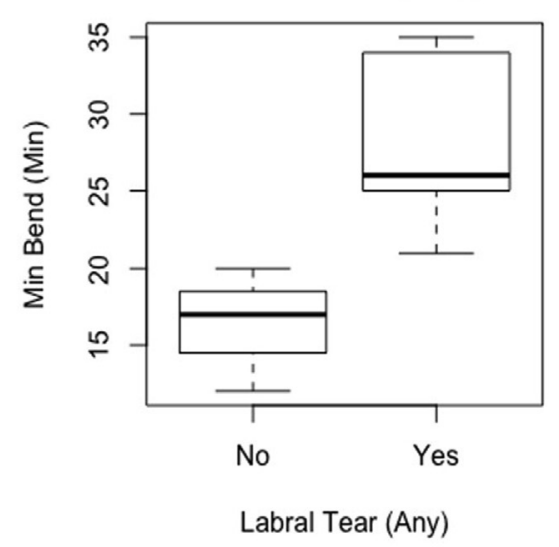

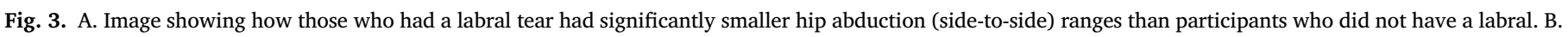
Image showing how those who had a labral tear had significantly higher hip flexion (bend) measures than participants who did not have a labral tear. 
as soccer, basketball, and ice hockey have repeatedly shown a higher prevalence of FAI morphology on imaging [6,18-20]. Recent data demonstrate that water polo players also have a higher incidence of FAI characteristics seen on MRI than the general population [9]. To date, there have been no published studies correlating radiographic FAI findings and hip biomechanics in water polo. Although this study has small numbers, there were a large percentage of players with evidence of labral and chondral pathology on MRI ( $25 \%$ and $37.5 \%$, respectively). For a young group of athletes, this is already a concerning trend, possibly secondary to the significant number of "treading water life-hours" put in by these athletes (over $9000 \mathrm{~h}$ on average in this cohort). Gaining a further understanding of how these two entities may be related is of utmost importance.

\section{Association with labral pathology}

The small sample size of our pilot study limited the significance of our findings, but some notable trends were identified. Participants who had a labral tear on MRI had significantly higher hip flexion (bend) measurements than those who did not have a labral tear $\left(28.2^{0} \pm 6.1^{0}\right.$ with a labral tear vs. $16.3^{0} \pm 4^{0}$ without, $\mathrm{p}=0.02$ ). Studies of other athletes in weight-bearing land sports have shown that higher hip flexion is correlated with increased FAI prevalence [20]. Interestingly, those participants with a labral tear had significantly smaller hip abduction (side-to-side) ranges than those who have not had a labral tear $\left(29^{0} \pm 4.1^{0}\right.$ with a labral tear vs. $35.3^{0} \pm 0.6^{0}$ without, $\left.\mathrm{p}=0.02\right)$. Whether this reduced motion is a protective mechanism is unclear at this time.

Further assessment of abduction ROM also showed that participants who have a labral tear of their left hip had significantly smaller abduction (side-to-side) ranges on the left hip than those who have not had a labral tear $\left(26^{0} \pm 2.6^{0}\right.$ vs. $\left.32^{0} \pm 3.5^{0}, \mathrm{p}=0.04\right)$. The authors find it interesting that these trends were not found on the contralateral side. With these trends however, this may mean that these participants with labral tears have increased flexion but limited abduction, which is not completely dissimilar to hip ROM found in other sports with higher FAI prevalence.

\section{Association with chondral pathology}

Participants who were found to have articular cartilage damage of their right hip had significantly higher minimum abduction (side-to-side) measures of the right hip than those who did not have chondral damage $\left(40^{0} \pm 1.4^{0}\right.$ in those with cartilage damage vs. $27.2^{0} \pm 10.3^{0}$ without, $\mathrm{p}=0.03$ ). Interestingly, this was not found to be statistically significant for the left hip however $\left(33.0^{0} \pm 5.7^{0}\right.$ with cartilage damage, vs. $22.7^{0} \pm$ $13.2^{0}$ without, $\mathrm{p}=0.19$ ), although it did trend in that direction. The difference may be in side dominance, although again, with a small sample size as with this pilot study, it is difficult to make any definitive conclusions. Similar to those participants with labral tears, limiting the range of abduction by maintaining a higher minimum abduction angle could place participants at a higher risk of FAI morphology. Alternatively, it is possible that those with this morphology are more likely to have limited abduction ranges. It is difficult to know however what is the cause versus the effect. This study also found no significant differences between right and left alpha angles $(\mathrm{p}=0.56)$ and no differences between right and left CEA $(\mathrm{p}=0.48)$ and no correlation between hip ROM and iHOT-33 results.

\section{Limitations}

This study has inherent limitations. Only elite college athletes were included, so results may not be extrapolated to younger or older players, as well as non-elite-level athletes; however, this group is a homogeneous group of athletes at the Olympic-quality level. Subjects were also majority female. Furthermore, because this was a pilot study with a small cohort of subjects, this may not have been enough to be able to sufficiently assess subtle correlations between imaging findings and hip ROM. There was no power analysis that was completed, so there is the risk of our findings being a result of beta-error. No physical examination was performed, limiting the ability to precisely determine hip functionality and real-time pain assessment. We measured the alpha angle using a coronal MRI image, which is not the ideal method as it primarily accounts for lateral or posterolateral CAM deformity. A radial MR or Dunn lateral x-rays would be an ideal addition to assess for deformity in other planes [21]. We also did not assess femoral version in this MR series, and we understand that changes to femoral version can alter the location of impingement lesions [22]. Similarly, the CEA is usually measured using plain radiographs of the pelvis. For the safety of these asymptomatic volunteers of young age, MRI measurements were utilised to avoid unnecessary radiation. The lateral aspect of the acetabulum on the MRI may not correlate with the shadow of the lateral aspect of the acetabulum, especially from an AP pelvis radiograph, where the beams are divergent. Thus, the precision of the CEA on MRI may not correlate with that of a plain radiograph. Further still, the so-called crossing sign is a radiographic finding of pincer impingement that cannot be inferred with the MRI. However, evaluating asymptomatic high-level water polo players both in the water for biomechanics and MRI is unique and helped provide some insight to determine if further study is warranted.

There may be other confounding variables for these varsity athletes that we are able to neither identify nor control for. These athletes participate in cross training on land, where they are subjected to ground/ axial forces. Thus, while most of the forces on their hips are rotational without axial forces, they are not without some ground axial forces as well. For years spent treading water and hours per week treading water, these numbers were self-reported, so these numbers were general estimates that may have been subject to recall bias. Differences in motion found during the egg-beater movement may also be due to inherent restrictions of hip ROM, which could be secondary to FAI or other alterations of hip anatomy that cannot be elucidated through our imaging modalities. Overall, long-term studies of athletes are warranted to assess how symptoms and ROM may change over time and how that correlates to imaging findings. Additionally, the findings of this pilot study warrant further study with larger numbers of elite subjects, as well as with athletes in varying age groups and levels.

\section{Conclusion}

Water polo players have a high prevalence of FAI anatomy, indicating that treading water may be a risk factor for FAI morphology. This study sheds more light on the possible biomechanical basis of FAI from the egg beater motion. Although there were no significant correlations with hip ROM and alpha angle or CEA angle, there were correlations between hip ROM and labral tears and cartilage damage. Namely, as hips had higher flexion and more limited hip abduction ranges, they were more likely to have labral pathology. The results of this pilot study demonstrate the need for further investigations into the correlations of hip ROM in water polo to FAI morphology with more study participants.

\section{Contributors}

$\mathrm{KH}$ collected video footage and analysed the video footage, collecting data within the animation software. JL organised MRI, collected data, and analysed imaging. NS assisted with statistical analysis. All authors, but mainly KH and MS, were responsible for the conception and design of the study. All authors participated in the consensus discussions. KH wrote the first draft of the manuscript with the help of JL, which was critically revised by all co-authors.

\section{Funding}

Funding was received a major grant from the Stanford University Vice Provost for Undergraduate Education as part of the Human Biology 
Honors Program. Support also came from GE Healthcare, and grants NIH EB002524 and NIH AR06206.

\section{Patient consent for publication}

Not required.

\section{Ethics approval}

Institutional Review Board approval was obtained from the Ethics Committee of Stanford University (IRB-41288).

\section{Provenance and peer review}

Not commissioned; externally peer reviewed.

\section{Data availability statement}

No data are available.

\section{Patient involvement}

No.

\section{Competing interests}

None declared.

\section{Acknowledgements}

The authors would like to thank the Stanford Athletics varsity water polo and synchronised swimming teams and coaches for allowing us to use them as subjects.

\section{Appendix A. Supplementary data}

Supplementary data to this article can be found online at https ://doi.org/10.1016/j.jisako.2021.10.003.

\section{References}

[1] Griffin DR, Dickenson EJ, O'Donnell J, et al. The Warwick Agreement on femoroacetabular impingement syndrome (FAI syndrome): an international consensus statement. Br J Sports Med 2016;50(19):1169-76. https://doi.org/ 10.1136/bjsports-2016-096743.

[2] Hack K, Di Primio G, Rakhra K, et al. Prevalence of cam-type femoroacetabular impingement morphology in asymptomatic volunteers. J Bone Joint Surg Am 2010; 92(14):2436-44. https://doi.org/10.2106/JBJS.J.01280.

[3] Riley GM, McWalter EJ, Stevens KJ, et al. MRI of the hip for the evaluation of femoroacetabular impingement; past, present, and future. J Magn Reson Imag 2015; 41(3):558-72. https://doi.org/10.1002/jmri.24725 [published Online First: 2014/ $08 / 23]$.

[4] Murray RO. The aetiology of primary osteoarthritis of the hip. Br J Radiol 1965; 38(455):810-24. https://doi.org/10.1259/0007-1285-38-455-810.

[5] Dooley PJ. Femoroacetabular impingement syndrome: nonarthritic hip pain in young adults. Can Fam Physician 2008;54(1):42-7
[6] Larson CM, Giveans MR, Samuelson KM, et al. Arthroscopic hip revision surgery for residual femoroacetabular impingement (FAI): surgical outcomes compared with a matched cohort after primary arthroscopic FAI correction. Am J Sports Med 2014; 42(8):1785-90. https://doi.org/10.1177/0363546514534181 [published Online First: 2014/05/29].

[7] Lynch TS, Bedi A, Larson CM. Athletic hip injuries. J Am Acad Orthop Surg 2017; 25(4):269-79. https://doi.org/10.5435/JAAOS-D-16-00171.

[8] Mountjoy M, Miller J, Junge A. Analysis of water polo injuries during 8904 player matches at FINA World Championships and Olympic games to make the sport safer. Br J Sports Med 2019;53(1):25-31. https://doi.org/10.1136/bjsports-2018-099349 [published Online First: 2018/09/07].

[9] Langner JL, Black MS, MacKay JW, et al. The prevalence of femoroacetabular impingement anatomy in Division 1 aquatic athletes who tread water. J Hip Preserv Surg 2020 Mar 26;7(2):233-41. https://doi.org/10.1093/jhps/hnaa009.

[10] Agricola R, Bessems JH, Ginai AZ, et al. The development of Cam-type deformity in adolescent and young male soccer players. Am J Sports Med 2012;40(5):1099-106. https://doi.org/10.1177/0363546512438381 [published Online First: 2012/03/ 13].

[11] Carter CW, Bixby S, Yen YM, et al. The relationship between cam lesion and physis in skeletally immature patients. J Pediatr Orthop 2014;34(6):579-84. https:// doi.org/10.1097/BPO.0000000000000177.

[12] Kienle KP, Keck J, Werlen S, et al. Femoral morphology and epiphyseal growth plate changes of the hip during maturation: MR assessments in a 1-year follow-up on a cross-sectional asymptomatic cohort in the age range of 9-17 years. Skeletal Radiol 2012;41(11):1381-90. https://doi.org/10.1007/s00256-012-1358-9 [published Online First: 2012/02/23].

[13] Agricola R, Heijboer MP, Ginai AZ, et al. A cam deformity is gradually acquired during skeletal maturation in adolescent and young male soccer players: a prospective study with minimum 2-year follow-up. Am J Sports Med 2014;42(4): 798-806. https://doi.org/10.1177/0363546514524364 [published Online First: 2014/02/28].

[14] Mohtadi NG, Griffin DR, Pedersen ME, et al. The Development and validation of a self-administered quality-of-life outcome measure for young, active patients with symptomatic hip disease: the International Hip Outcome Tool (iHOT-33). Arthroscopy 2012;28(5):595-605. https://doi.org/10.1016/j.arthro.2012.03.013. quiz 06-10.e1.

[15] Krosshaug T, Bahr R. A model-based image-matching technique for threedimensional reconstruction of human motion from uncalibrated video sequences. J Biomech 2005;38(4):919-29. https://doi.org/10.1016/j.jbiomech.2004.04.033.

[16] Nötzli HP, Wyss TF, Stoecklin $\mathrm{CH}$, et al. The contour of the femoral head-neck junction as a predictor for the risk of anterior impingement. J Bone Joint Surg Br 2002;84(4):556-60. https://doi.org/10.1302/0301-620x.84b4.12014.

[17] Frank JM, Harris JD, Erickson BJ, et al. Prevalence of femoroacetabular impingement imaging findings in asymptomatic volunteers: a systematic Review. Arthroscopy 2015;31(6):1199-204. https://doi.org/10.1016/j.arthro.2014.11.042 [published Online First: 2015/01/28].

[18] Philippon MJ, Ho CP, Briggs KK, et al. Prevalence of increased alpha angles as a measure of cam-type femoroacetabular impingement in youth ice hockey players. Am J Sports Med 2013;41(6):1357-62. https://doi.org/10.1177/ 0363546513483448 [published Online First: 2013/04/05]

[19] Siebenrock KA, Ferner F, Noble PC, et al. The cam-type deformity of the proximal femur arises in childhood in response to vigorous sporting activity. Clin Orthop Relat Res 2011;469(11):3229-40. https://doi.org/10.1007/s11999-011-1945-4 [published Online First: 2011/07/15].

[20] Falotico GG, Arliani GG, Yamada AF, et al. Professional soccer is associated with radiographic cam and pincer hip morphology. Knee Surg Sports Traumatol Arthrosc 2018. https://doi.org/10.1007/s00167-018-5008-1 [published Online First: 2018/ 06/06].

[21] Mascarenhas VV, Caetano A, Dantas P, et al. Advances in FAI imaging: a focused Review. Curr Rev Musculoskelet Med 2020;13(5):622-40. https://doi.org/ 10.1007/s12178-020-09663-7.

[22] Lerch TD, Boschung A, Todorski IAS, et al. Femoroacetabular impingement patients with decreased femoral version have different impingement locations and intra- and extraarticular anterior subspine FAI on 3D-CT-based impingement simulation: implications for hip arthroscopy. Am J Sports Med 2019;47(13):3120-32. https:// doi.org/10.1177/0363546519873666 [published Online First: 2019/09/20]. 